\title{
ALGUMAS DIMENSÕES DA "DIFERENÇA": O ITINERARIO DE GILLES DELEUZE NO ARTIGO "A CONCEPÇÃO DA DIFERENÇA EM BERGSON”**
}

\author{
Flávio Luiz Freitas** \\ f_lcf@hotmail.com
}

RESUMO $O$ objetivo do presente trabalho consiste em explicitar o itinerário ou linha argumentativa de Gilles Deleuze no artigo intitulado "A concepção da diferença em Bergson”, de 1954. Postula-se que nesse trabalho de 1954, Deleuze exponha a noção de 'diferença', que está presente na obra de Henri Bergson, por meio da relação entre três dimensões: metodológica, cosmológica e ontológica. Para tanto, caracteriza-se o conjunto do pensamento de Deleuze em relação à História da Filosofia. Em seguida, identifica-se o percurso das pesquisas de Deleuze sobre a obra de Bergson no contexto de sua versão para a História da Filosofia. Por fim, explicita-se o itinerário de Deleuze no artigo de 1954: "A concepção da diferença em Bergson”.

Palavras-chave Deleuze, Bergson, História da Filosofia, Diferença.

ABSTRACT The purpose of this paper is to explain the itinerary or argumentative line of Gilles Deleuze in the article named "The conception of difference in Bergson" of 1954. It is postulated that in this work of 1954, Deleuze exposes the notion of "difference", which is present in the work of Henri Bergson, through the relation between three dimensions: the methodological,

* Artigo submetido em 26/06/2017. Aceito em 23/08/2017.

** UFMA - Universidade Federal do Maranhão, São Luís, MA, Brasil; UFSCar - Universidade Federal de São Carlos, São Carlos, SP, Brasil. 
cosmological and ontological ones. For that purpose, the whole of Deleuze's thought in relation to the History of Philosophy is characterized. Then, we identify the course of Deleuze's research on Bergson's work in the context of his version for the History of Philosophy. Finally, we explain the itinerary of Deleuze in the article of 1954: "The conception of difference in Bergson".

Keywords Deleuze, Bergson, History of Philosophy, Difference.

\section{Introdução}

O objetivo do presente trabalho consiste em explicitar o itinerário ou linha argumentativa de Gilles Deleuze no artigo intitulado "A concepção da diferença em Bergson", de 1954. Postulamos que nesse trabalho de 1954 Deleuze exponha a noção de 'diferença' que está presente na obra de Henri Bergson por meio do entrelaçamento de três dimensões: metodológica, cosmológica e ontológica.

Para desenvolver nosso objetivo, contextualizaremos o conjunto do pensamento de Deleuze em relação à História da Filosofia. Em seguida, iremos caracterizar, brevemente, o percurso das pesquisas de Deleuze sobre a obra de Bergson nesse contexto. Por fim, nos dedicaremos a descrever o itinerário de Deleuze no artigo de 1954: "A concepção da diferença em Bergson".

É oportuno ressaltar que existem três textos de Deleuze a respeito do pensamento de Bergson: "A concepção da diferença em Bergson”, de 1954; "Bergson, 1859-1941", de 1956; e "Bergsonismo", de 1966. Nos limites de nosso objetivo, a justificativa para escolhermos o artigo de 1954 concerne ao fato de que ele é o primeiro trabalho de Deleuze sobre Bergson. Além disso, entendemos que esse trabalho contém a matriz argumentativa que será retomada no texto de 1956 denominado de "Bergson, 1859-1941" e detalhada no livro de 1966, isto é, "Bergsonismo".

\section{A História da Filosofia e os estudos bergsonianos em Deleuze}

Caso adotemos duas partes distintas de Conversações, de 1990, como referência para a divisão do conjunto do pensamento de Deleuze, poderemos encontrar relevantes coordenadas para situar e localizar suas pesquisas que são pertinentes à obra de Bergson.

A primeira parte está presente na "Carta a um crítico severo", datada originalmente de 1972, na qual Deleuze afirma que "fez" por muito tempo História da Filosofia. No entanto, era um tipo de História da Filosofia oposta 
à tradição racionalista mediante um procedimento denominado de "imaculada concepção".

Semelhante oposição significava escolher autores que estivessem relacionados por meio de um vínculo secreto forjado pela cultura da alegria, pela crítica do negativo, pela denúncia do poder, dentre outros temas. Naquilo que tange ao procedimento da imaculada concepção, ele consiste em contestar, descentralizar e subverter as chaves de leitura hegemônicas que tratavam de determinado autor. Uma chave de leitura é constituída pelo conjunto de hipóteses, linhas argumentativas e conclusões sobre um segmento ou o conjunto do pensamento de determinado filósofo. Nos termos desse contexto, Deleuze compreende seu trabalho acerca da obra de Bergson como sendo exemplar. ${ }^{1}$

A segunda parte de "Conversações" em que Deleuze trata do conjunto de seu pensamento está exposta numa entrevista de 1988 concedida ao "Magazine Littéraire". Nessa ocasião, Deleuze afirma que sua obra pode ser dividida em três momentos. O primeiro momento também concerne ao processo de "fazer" História da Filosofia, tal qual na divisão apresentada em 1972, conforme mencionamos anteriormente.

O segundo momento diz respeito à tarefa de criar seus próprios conceitos. Nesse caso, isso decorre da parceria com Félix Guattari, da qual o produto é o projeto "Capitalismo e Esquizofrenia", cujo percurso vai da teoria do desejo em "O Anti-Édipo", de 1972, à teoria das multiplicidades de "Mil Platôs", de 1980.

O terceiro momento trata explicitamente de seus estudos sobre estética e Filosofia da Arte, dentre os quais estão os trabalhos sobre cinema e pintura, que correspondem aos afectos e perceptos. Com relação a esse momento, podemos enfatizar "Francis Bacon: Lógica da Sensação", "Cinema 1-A imagem movimento" e "Cinema 2 - A imagem tempo". Nessa divisão, que remete ao ano de 1988, os trabalhos sobre Bergson estão também inseridos no período ou momento dedicado à História da Filosofia.

Cabe ainda retomar o Prólogo de "Diferença e repetição" de 1968, no qual Deleuze sustenta que o ponto de vista de um projeto voltado para criticar a representação e para pensar a diferença em si mesma e a relação do 'diferente' com o 'diferente', vindo alcançar o mundo dos simulacros e do sem-fundo na repetição pura, existe um procedimento específico que pode ser utilizado nas pesquisas em História da Filosofia:

Parece-nos que a História da Filosofia deve desempenhar um papel bastante análogo ao da colagem numa pintura. A História da Filosofia é a reprodução da própria Filosofia. 
Seria preciso que a resenha em História da Filosofia atuasse como um verdadeiro duplo e que comportasse a modificação máxima própria do duplo (Deleuze, 2006, p. 18).

Esse procedimento é a 'colagem'. A colagem, análoga à pintura, pode ser caracterizada como uma resenha capaz de produzir um verdadeiro duplo, o qual comporta a modificação máxima de si mesmo no mesmo movimento em que transforma o texto inicialmente resenhado. "Comportar a modificação máxima de si mesmo" significa estar aberto para novas chaves de leitura e interpretações portadoras de profunda estranheza. Portanto, a colagem pode ser considerada um descentramento e uma subversão.

É prudente destacar a ambiguidade que o estatuto da História da Filosofia adquire para Deleuze ao longo do tempo. O núcleo dessa ambiguidade é composto pela oscilação entre a repressão e a propedêutica. Uma vez assegurado seu próprio procedimento de reivindicação e confronto para com a História da Filosofia, o pensamento de Deleuze oscila entre a repressão e a necessidade propedêutica em relação ela.

Como repressão, a História da Filosofia tem duas imagens interessantes. A primeira imagem está colocada na "Carta a um crítico severo". Nessa imagem, a História da Filosofia é comparada ao "Édipo" da própria Filosofia, cuja função consiste em dizer o que deve ser lido ou pensado antes de abordarmos determinado autor. A segunda imagem está presente nos "Dialogues" com Parnet.

Nessa segunda imagem, a História da Filosofia equivale ao "agente de poder" que é direcionado para reprimir ao gênese do ato de pensar no próprio pensamento. O curioso é que cada imagem da História da Filosofia parece estar indiretamente relacionada a uma imagem do pensamento, isto é, ao conjunto de coordenadas e pressupostos relativos ao significado do que seja pensar.

Se cada História da Filosofia é a reprodução da Filosofia, a própria Filosofia é a reprodução de, pelo menos, uma imagem do pensamento específica. Logo, a noologia, como estudo sobre imagem do pensamento precede à Filosofia, que por seu turno precede à História da Filosofia. Então, escrever, resenhar e comentar em História da Filosofia significa reproduzir determinada Filosofia e, no extremo, reproduzir também a imagem do pensamento que está relacionada a essa Filosofia.

Por outro lado, como propedêutica, a História da Filosofia é considerada por Deleuze no "L'Abécédaire", de 1988, especificamente no verbete " $H$ " referente à "História da Filosofia", como uma arte do retrato e o processo necessário para o aprendizado da criação dos conceitos. ${ }^{2}$ Deleuze alega que foi indispensável 
fazer História da Filosofia durante muito tempo para conseguir alcançar o mundo dos conceitos. Sua comparação é com a do ofício do jovem romancista, para o qual é necessário ler outros autores para acessar o processo de criação literária. Nesse caso, a História da Filosofia é a condição para o surgimento da tarefa destinada à fabricação de conceitos.

Sendo assim, a ambiguidade do estatuto da História da Filosofia ao longo do pensamento de Deleuze oscila entre a repressão e a preparação introdutória (ou propedêutica) para a atividade de criação de conceitos e efetivo exercício do pensamento filosófico.

Dessa maneira, à luz dessa História da Filosofia heterodoxa, vitalista, diferencial e ambígua voltada para realizar descentramentos, deslizes e subversões, as relações entre Deleuze e Bergson ${ }^{3}$ podem ser pensadas, a princípio, na matriz que se desenvolve entre 1954 e $1966 .{ }^{4}$ Com base especificamente no exercício do procedimento da "imaculada concepção", o texto de 1954, "A concepção da diferença em Bergson", tenta retirar o conceito de duração do psicologismo, lançando-a numa dimensão ontológica.

Tamanha movimentação da duração, que vai do psicológico ao ontológico, demarca uma verdadeira subversão e contestação das chaves de leitura hegemônicas acerca do pensamento de Bergson, carregando, ainda, a possibilidade do duplo a respeito de si mesma. Uma dessas chaves de leitura hegemônicas e corrosivas corresponde ao livro de Georges Politzer publicado em 1929, cujo título é "La fin d'une parade philosophique, lebergsonisme". O detalhe interessante é que Politzer utilizou o pseudônimo anticlerical François Arouet para publicar esse trabalho.

No trabalho de 1956, intitulado de "Bergson, 1859-1941", ${ }^{5}$ que compõe a coletânea "Les philosophes célèbres", organizada por Merleau-Ponty, Deleuze

3 Sobre a importância que a filosofia de Bergson exerce no pensamento de Deleuze, é indispensável mencionar a dupla hipótese de Alliez, que preconiza o seguinte: em seu aspecto mínimo, o bergsonismo de Deleuze investe na questão da diferença como meio de destruição do bergsonismo estabelecido, o qual é orientado na direção de uma metafísica espiritualista. Em seu aspecto máximo, a hipótese de Alliez defende que é possível apreender no bergsonismo de Deleuze a heterogênese em ato do pensamento do próprio Deleuze, tanto no nível do sistema quanto no nível do método. Cf: Alliez (2000, p. 246).

4 Acerca do percurso dessa matriz que se desenvolve entre 1954 e 1966, Hardt tem um entendimento valioso, segundo o qual os trabalhos de Deleuze sobre Bergson se desenvolvem antes e depois de "Nietzsche e a filosofia", que foi publicado em 1962. No entendimento de Hardt, o traço distintivo e marcante entre esses dois períodos de pesquisas deleuzianas a respeito da obra de Bergson consiste na mudança da prioridade do objeto de antagonismo. Antes de "Nietzsche e a filosofia", Deleuze destaca, prioritariamente, a contenda de Bergson para com o movimento negativo da determinação. Depois de "Nietzsche e a filosofia", Deleuze enfatiza o antagonismo de Bergson em relação ao Uno e o Múltiplo. "A obra de Deleuze sobre Bergson, todavia, apresenta uma complicação - ao mesmo tempo uma oportunidade para o estudo da evolução do seu pensamento, porque é conduzida em dois períodos distintos: um em meados dos anos 50 e outro em meados dos anos 60" (Hardt, 1996, p. 28).

5 "O nome de Bergson permanece ligado às noções de duração, memória, impulso vital, intuição. Sua influência e seu gênio se avaliam graças à maneira pela qual tais conceitos se impuseram, foram utilizados, entraram 
destaca a importância da intuição como método dotado de precisão para identificar os falsos problemas e permitir construir problemas verdadeiros. Além de frisar como os principais conceitos dessa filosofia as noções de duração, impulso vital e memória.

Já no o livro de 1966, "Bergsonismo", ${ }^{6}$ Deleuze investiga o seguinte problema: qual é a relação que pode ser estabelecida entre as noções de Duração, Memória e Impulso Vital? Ademais, qual é o progresso que elas implicam? Uma das principais teses para desenvolver esse problema postula que a intuição, entendida como método rigoroso, pode determinar as relações entre essas noções. ${ }^{7}$

\section{O itinerário do artigo de 1954}

Um dos principais objetivos de Deleuze no texto "A concepção da diferença em Bergson" consiste em demonstrar que a filosofia de Bergson está voltada para realizar um duplo movimento complementar, o qual é constituído por uma seara propositiva e por um âmbito crítico.

A seara propositiva está voltada para apresentar a diferença em pelo menos três importantes sentidos. No primeiro sentido, a diferença é caracterizada como diferença vital. No sentido seguinte, a diferença é compreendida como virtual, que por sua vez corresponde à identidade entre o conceito e o objeto. $\mathrm{O}$ terceiro sentido advoga que a diferença consiste numa novidade. Por outro lado, o âmbito crítico investiga em que medida a concepção da diferença em Bergson é uma pura diferença interna. Pura diferença interna significa puro conceito da diferença, sem reduzi-lo à pluralidade, à contradição e ao negativo. ${ }^{8}$

Para cumprir esse duplo intento, o itinerário de Deleuze busca agrupar quatro aspectos: diferenças de natureza, diferença interna, diferenciação e, por fim, graus da diferença. Sua justificativa para essa pesquisa parte do pressuposto de que o bergsonismo deve trazer a maior contribuição para a filosofia da diferença, pois trabalha com um plano metodológico e com um plano ontológico, que, além de fazerem a constante remissão de um ao outro, também correspondem, respectivamente, ao problema das diferenças de natureza e ao problema da

e permaneceram no mundo filosófico" (Deleuze, 2006, p. 33).

6 Dosse (2010, p. 120). O próprio título de sua obra se reveste de um tom provocativo, em ruptura com a doxa em vigor sobre Bergson. O que prevalece a propósito de Bergson é a interpretação ultracrítica feita antes da guerra por Georges Politzer. Com o pseudônimo anticlerical François Arouet, Georges Politzer publicou em 1929 um livro bastante corrosivo contra o bergsonismo.

7 "Duração [Durée], Memória [Mémoire] e Impulso vital [Élan vital] marcam as grandes etapas da filosofia bergsoniana. O objetivo deste livro é a determinação da relação entre essas três noções e do progresso que elas implicam" (Deleuze, 1999, p. 7). 
natureza da diferença. Portanto, a diferença na dimensão metodológica equivale ao tema das diferenças de natureza e a diferença na dimensão ontológica está ligada ao problema da natureza da diferença:

A noção de diferença deve lançar uma certa luz sobre a filosofia de Bergson, mas, inversamente, o bergsonismo deve trazer a maior contribuição para uma filosofia da diferença. Uma tal filosofia opera sempre sobre dois planos, metodológico e ontológico. De um lado, trata-se de determinar as diferenças de natureza entre as coisas: é somente assim que se poderá "retornar" às próprias coisas, dar conta delas sem reduzi-las a outra coisa, apreendê-las em seu ser. Mas, por outro lado, se o ser das coisas está de um certo modo em suas diferenças de natureza, podemos esperar que a própria diferença seja alguma coisa, que ela tenha uma natureza, que ela nos confiará enfim o Ser. Esses dois problemas, metodológico e ontológico, remetem-se perpetuamente um ao outro: o problema das diferenças de natureza e o da natureza da diferença. Em Bergson, nós os reencontramos em seu liame, nós surpreendemos a passagem de um ao outro (Deleuze, 2006, p. 47).

A justificativa dessa investigação de Deleuze também está aliada à inspiração fenomenológica de retornar às próprias coisas; e de estabelecer, filosoficamente, relações positivas e diretas com elas, evitando, assim, uma relação negativa e genérica. Uma relação positiva e direta para com as coisas é marcada pelo projeto de apreender a diferença interna de cada coisa.

Por isso, para Deleuze, como leitor de Bergson, retornar às próprias coisas significa estabelecer as diferenças de natureza como meio e a diferença interna como o fim a ser atingido, uma vez que cabe à filosofia talhar para o objeto um conceito que seja apropriado somente para esse objeto. Tamanha identidade entre o conceito e o objeto é a diferença interna, cujo ponto de partida é a diferença de natureza.

Com base nisso, Deleuze expõe que é necessário, em primeiro lugar, encontrar e identificar as diferenças de natureza, com a condição de não prejulgar a natureza da diferença como diferença interna. Assim, trata-se da dimensão metodológica. O método para encontrar e identificar as diferenças de natureza é a intuição, a qual tem pelo menos dois esforços.

O primeiro esforço da intuição é chamado de "empirismo", que procede cortando e dividindo a realidade segundo suas articulações, "as articulações do real". Esse primeiro esforço distribui as coisas segundo suas diferenças de natureza para formar diferenciações. O segundo esforço é chamado de "probabilismo", o qual procede por intersecção, identificando "as linhas de fatos", suas direções e pontos de convergência para uma única e mesma coisa, em que cada linha caracteriza uma probabilidade. Esse ponto de encontro entre as linhas de fato é a própria diferença interna. Por isso o real é aquilo que se corta e se intersecciona. 
Ocorre que, com base no âmbito crítico do pensamento de Bergson, Deleuze explica que as diferenças de natureza foram "perdidas". Essa perda decorre de uma dupla substituição. A atividade científica substituiu as diferenças de natureza pelas diferenças de grau, bem como a metafísica substituiu as diferenças de natureza pelas diferenças de intensidade. É oportuno ressaltar que tamanha perda também culmina na construção daquilo que Bergson nomeou de "falsos problemas", cujo núcleo está voltado para não respeitar no seu enunciado as diferenças de natureza.

Essa primeira camada do âmbito crítico tem o objetivo de problematizar os graus para retomá-los a partir do plano da duração ou como graus coexistentes na memória. Criticar significa problematizar para transformar e inverter.

Nesse caso, é atribuída à atividade científica a responsabilidade em substituir as diferenças de natureza pelas diferenças de grau quando utiliza o ponto de vista utilitário para construir seus agrupamentos. Esse ponto de vista utilitário libera e expõe os graus que estão presentes de alguma maneira nas diferenças de natureza até que elas sejam convertidas apenas em diferenças de grau.

A razão disso está no estado da experiência, o qual resulta daquilo que o espaço apresenta ao entendimento, ou seja, o espaço apresenta coisas, produtos e resultados. Contudo, as diferenças de natureza não estão em meio às características, coisas, produtos e resultados. As diferenças de natureza estão nas tendências em desenvolver características. Segundo Deleuze, uma coisa é a expressão de uma tendência antes de ser o efeito de uma causa. ${ }^{9}$ Por consequência, uma diferença de grau é o estatuto das coisas separadas de suas tendências e consideradas a partir de suas causas elementares.

As características, coisas, produtos e resultados que integram o estado da experiência são mistos ou misturas homogêneas entre tendências que diferem por natureza. No entanto, por serem misturas são também estados de coisas nos quais não é possível apontar as diferenças de natureza.

O interessante é que Deleuze caracteriza os mistos como aquilo "que se vê do ponto de vista em que, por natureza, nada difere de nada". ${ }^{10}$ Assim, para atingir, encontrar e identificar as diferenças de natureza, Deleuze esclarece que é necessário adotar como ponto de partida os mistos de diferenças de graus para que eles sejam pensados como medidas das tendências, já que eles são os únicos indícios existentes, inicialmente, para essa tarefa.

No que diz respeito à metafísica, ela contribuiu para a perda das diferenças de natureza na ocasião em que as substituiu pelas diferenças de intensidade. 
As diferenças de intensidade são aquelas que situam os seres entre os limites opostos de uma perfeição e de um nada. Inclusive o espaço e o tempo são definidos nos termos desse intervalo entre a perfeição e nada, isto é, são definidos como simples distensão ou diminuição de ser. Como característica ou segunda camada do âmbito crítico do pensamento de Bergson, Deleuze enfatiza que a problematização acerca das diferenças de intensidade significa também a reapropriação delas a partir da contração e da distensão como princípios de explicação fundamentais. ${ }^{11}$

Dessa maneira, o passo inicial para encontrar e identificar as diferenças de natureza consiste nas medidas das tendências ou nas diferenças de grau, mais especificamente nos mistos que compõe o estado da experiência. Feito isso, Deleuze ensina que é necessário reencontrar o ponto de vista que permite dividir o misto em tendências que se opõe uma à outra. Nesses termos, os verdadeiros sujeitos não são os seres, mas as tendências. Os seres, por sua vez, são a expressão do confronto entre duas tendências opostas.

O ponto de vista que permite essa divisão dos mistos em tendências opostas é o do método da intuição, que funciona, nesse caso, como um método da diferença ou da divisão. O procedimento do método da intuição está entre uma descrição da experiência e uma análise transcendental, pois aborda as condições daquilo que é dado. Essas condições são as tendências-sujeito como elemento vivido. Se o método da intuição está entre a descrição da experiência e a análise transcendental, ele investiga, precisamente, as condições da experiência real de algo e não as condições de toda experiência possível.

As condições da experiência real dizem respeito ao fundamento constatado, vivido e dotado de certo caráter empírico. Esse tipo de condicionante nunca pode ser maior do que o condicionado, uma vez que o conceito que essas condições formam é idêntico ao objeto. Para que isso aconteça, essa identidade entre o conceito e o objeto é a própria tendência, a qual só pode ser apreendida numa intuição, pois ela não é uma característica, coisa, resultado ou produto. Portanto, essa pesquisa, mediante o método da intuição, para identificar as condições da experiência real, recebe o nome de "empirismo superior".

Deleuze adverte que mesmo com uma descrição precisa do método, ele não está isento de incorrer num impasse. Esse impasse é composto por três momentos que estão interligados, os quais podem ser enunciados em três perguntas distintas: como encontrar as tendências em meio as diferença de grau? Qual regra adotar para dividir essas tendências? Qual é a boa tendência? 
Essas três perguntas podem ser respondidas por meio da noção chamada de "tendência dominante". Para Deleuze, à luz de "Matéria e Memória", de Bergson, uma tendência dominante é aquela que define a verdadeira natureza do misto que compõe o estado da experiência. Essa definição da verdadeira natureza do misto decorre da tendência dominante ser também a única tendência pura, visto que apenas ela é o conceito único ou a unidade entre o conceito e a coisa.

Isso significa que a tendência dominante é o critério a ser utilizado para encontrar tanto a si quanto a tendência impura nas diferenças de grau. Além disso, a tendência dominante é a regra para dividir o misto em duas tendências e, por fim, a tendência dominante é a boa tendência, devido ela corresponder à unidade entre a coisa e o conceito.

A consequência disso consiste em postular que a diferença de natureza não está entre as tendências, pois ela é a própria tendência dominante. Mais especificamente, ela é a própria duração ou aquilo que difere de si. Não apenas isso, mas baseado em "Pensamento Movente", de Bergson, Deleuze sustenta que a duração é tendência-sujeito-substância e sua essência é o movimento como caráter substancial da realidade que não pressupõe coisa alguma. Portanto, nos termos da dimensão ontológica, a boa tendência é o movimento como substância que dispensa pressupostos.

A duração como tendência-sujeito-substância, que difere de si, é caracterizada como sendo simples, indivisível e pura. A partir dessa simplicidade, dessa indivisibilidade e dessa pureza, Deleuze pergunta: de que maneira a duração difere de si? De início, ele esclarece que não é do mesmo modo tal qual o misto pode ser dividido, porém enfatiza que o misto é dividido em duas tendências, das quais uma é pura e a outra impura. Sendo que a tendência pura dominante é a substância, a qual não pode ser dividida em função de sua simplicidade e de sua indivisibilidade. Logo, essa é a dimensão ontológica da diferença.

Para chegar às verdadeiras diferenças, é preciso reencontrar o ponto de vista que permita dividir o misto. São as tendências que se opõem duas a duas, que diferem por natureza. A tendência é que é sujeito. Um ser não é o sujeito, mas a expressão da tendência, e, ainda, um ser é somente a expressão da tendência à medida que ela é contrariada por uma outra tendência. Assim, a intuição apresenta-se como um método da diferença ou da divisão: dividir o misto em duas tendências. Esse método é coisa distinta de uma análise espacial, é mais do que uma descrição da experiência e menos (aparentemente) do que uma análise transcendental. Ele eleva-se até as condições do dado, mas tais condições são tendências-sujeito, são elas mesmas dadas de uma certa maneira, são vividas (Deleuze, 2006, p. 51).

Ocorre que se a tendência-sujeito-substância não realiza sobre si mesma uma divisão, pelo menos não no início, seu movimento ou processo é de diferenciação. A tendência-sujeito-substância se diferencia em duas outras 
tendências e Deleuze enfatiza que como essa tendência dominante é a própria duração, ela se diferencia em contração e distensão, essa última é o princípio da matéria.

Desse modo, o método da diferença é composto por dois movimentos: dividir e diferenciar. Contudo, é o poder de diferenciação que conduz e que leva ao puro conceito da diferença. A diferença interna ou duração é o virtual, que enquanto indivisível não deixa de se dividir. Porém, quando finalmente se divide, muda de natureza. Assim, a diferença interna é uma diferença vital, que sofre diferenciação, ${ }^{12}$ marcada pela indeterminação. A diferença é vital ${ }^{13}$ pois a vida é processo indeterminado da diferença. Nesse caso, a indeterminação, no sentido da evolução da vida, é o imprevisível, mas ao mesmo tempo é o essencial e a negação do acidente.

Mas é, sobretudo, em A evolução criadora que acharemos os ensinamentos necessários. A biologia nos mostra o processo da diferenciação operando-se. Buscamos o conceito da diferença enquanto esta não se deixa reduzir ao grau, nem à intensidade, nem à alteridade, nem à contradição: uma tal diferença é vital, mesmo que seu conceito não seja propriamente biológico. A vida é o processo da diferença. Aqui Bergson pensa menos na diferenciação embriológica do que na diferenciação das espécies, ou seja, na evolução. Com Darwin, o problema da diferença e o da vida foram identificados nessa idéia de evolução, ainda que Darwin, ele próprio, tenha chegado a uma falsa concepção da diferença vital. Contra um certo mecanicismo, Bergson mostra que a diferença vital é uma diferença interna. Mas ele também mostra que a diferença interna não pode ser concebida como uma simples determinação: uma determinação pode ser acidental, ao menos ela só pode dever o seu ser a uma causa, a um fim ou a um acaso, implicando, portanto, uma exterioridade subsistente; além do mais, a relação de várias determinações é tão-somente de associação ou de adição. A diferença vital não só deixa de ser uma determinação, como é ela o contrário disso; é, se, se quiser, a própria indeterminação (Deleuze, 2006, p. 57).

A diferenciação, que é o processo da própria diferença vital, decorre da força explosiva interna que a vida carrega consigo combinada à resistência encontrada pelo lado da matéria. A essência de uma tendência vital ou virtual é se

12 Freitas (2015, pp. 100-117).

13 Bergson (2005, p. 107). O movimento evolutivo seria coisa simples, seria coisa rápida determinar sua direção, se a vida descrevesse uma trajetória única, comparável à de uma bala maciça lançada por um canhão. Mas lidamos aqui com um obus que imediatamente explodiu em fragmentos, os quais, sendo eles próprios espécies de abuses, explodiram por sua vez em fragmentos destinados a novamente explodirem e assim por diante, durante muito tempo. Só percebemos aquilo que está mais perto de nós, os movimentos espalhados dos fragmentos pulverizados. E partindo deles que precisamos subir de volta, degrau por degrau, até o movimento original. Quando o obus explode, sua fragmentação particular explica-se tanto pela força explosiva da pólvora que ele contém quanto pela resistência que o metal lhe opõe. O mesmo vale para a fragmentação da vida em indivíduos e espécies. Esta, cremos, prende-se a duas séries de causas: a resistência que a vida experimenta por parte da matéria bruta e a força explosiva devida a um equilíbrio instável de tendências - que a vida carrega em si. 
desenvolver em feixe, ou seja, diferenciação é o movimento de uma virtualidade que se atualiza. Portanto, diferenciar significa também desenvolver feixes em direções divergentes nos quais será distribuído o impulso vital. Portanto, a diferenciação carrega consigo a dimensão cosmológica da diferença.

Com base nisso, a diferenciação tem três características marcantes: simplicidade de um virtual, divergência das séries nas quais ela se realiza e semelhança de certos resultados fundamentais que são produzidos nessas séries. Nesse caso, a semelhança é biologicamente importante, visto que ela é a identidade do que difere de si mesmo e, ainda, ela mostra a essência subsistindo na mudança.

Deleuze argumenta que, em "As duas fontes", Bergson apresenta dois tipos de diferenciação: uma diferenciação biológica e uma diferenciação histórica. A diferenciação biológica encontra seu princípio na própria vida e está ligada à matéria, uma vez que a materialidade que as espécies deram para si mesmas as impede de voltar a reunir-se para restabelecer à tendência original. $\mathrm{Na}$ diferenciação histórica, é no mesmo indivíduo e na mesma sociedade que as tendências evoluem e se constituem por dissociação. Mais especificamente, essas tendências evoluem no homem e isso demarca a distinção do histórico em relação ao vital. Demarcando, assim, o biológico e o histórico como faces da dimensão cosmológica da diferença.

Nessa especificidade, a diferença toma consciência de si por meio do homem. Enquanto a própria diferença é biológica, a consciência da diferença é histórica. Ocorre que a duração/vida é, de direito, por si mesma, consciência, visto que a consciência já estava aí com e na própria diferença. De um ponto de vista do fato, a história é o lugar onde a consciência se reanima, mas isso não significa que a consciência em Bergson seja histórica. Existe uma identidade de direito entre consciência da diferença e diferença, a qual é a própria memória, que encaminha para a natureza do puro conceito.

Deleuze alerta que a diferenciação não é o elemento mais profundo na busca pelo conceito que seja idêntico ao seu objeto. A diferenciação é uma ação ou realização do virtual que produz objetos que encontram sua razão no conceito. A condição para que o virtual possa produzir os objetos durante seu processo de diferenciação é de que ele seja dotado de uma consistência objetiva capaz de permitir a diferenciação.

Essa consistência do virtual é constituída por nuanças ou graus do conceito. As nuanças ou graus são as próprias coisas que coexistem no conceito mediante uma relação de participação, de coparticipação, e não de subsunção. Assim, o virtual ou o conceito é a diferença interna, cuja consistência é forjada pela diferença entre os objetos que estão relacionados nele. $\mathrm{O}$ efeito disso é que o conceito pode ser compreendido como um universal concreto sem ser convertido 
numa generalidade ou num gênero. Por isso, o virtual é a dimensão ontológica da diferença, cuja profundidade corresponde à relação de igualdade entre o conceito e seu respectivo objeto.

O conceito como universal concreto permite compreender o particular, já que está no extremo do particular, isto é, ele é o ponto de convergência para o qual todas as direções das linhas de fato apontam, ao mesmo tempo em que as articulações do real desenham as linhas de fato que mostram o conceito como limite dessa convergência. O empirismo remete a um probabilismo e vice-versa.

Esse conceito puro, universal e concreto é o virtual dotado de toda sua consistência objetiva, a qual é caracterizada pela coexistência das coisas como graus ou nuanças. Os graus ou nuanças podem ser compreendidos como planos virtuais de contração ou níveis de tensão. Semelhante coexistência entre os planos virtuais de contração ou níveis de tensão recebe o nome de "memória".

Para Deleuze, com base em "Matéria e Memória", ${ }^{14}$ esse aspecto pertinente à memória demarca a cosmologia na filosofia de Bergson, na qual tudo é mudança de tensão e de energia. Essa memória integra um dos três aspectos do conceito ou virtual, os outros dois aspectos são a duração e o impulso vital.

Entre esses três aspectos há uma relação de profundidade gradativa, isto é, a duração é o aspecto mais profundo, que por sua vez é seguido pela memória, a qual é seguida pelo impulso vital. A duração é a diferença para consigo mesma; a memória é a coexistência dos graus da diferença; e o impulso vital é a diferenciação da diferença. Essa relação de profundidade gradativa entre os três aspectos do conceito ou virtual tem um funcionamento dinâmico, embora possa ser descrita em termos de um esquematismo, que Deleuze denominou de "níveis do esquematismo da filosofia de Bergson".

A duração é a diferença consigo mesma; a memória é a coexistência dos graus da diferença; o impulso vital é a diferenciação da diferença. Esses três níveis definem um esquematismo na filosofia de Bergson. O sentido da memória é dar à virtualidade da própria duração uma consistência objetiva que faça desta um universal concreto, que a torne apta a se realizar. Quando a virtualidade se realiza, isto é, quando ela se diferencia, é pela vida e é sob uma forma vital; nesse sentido, é verdadeiro que a diferença é vital.

14 Bergson (1999, p. 237). A bem da verdade, turbilhões e linhas de força não são jamais, no espírito do físico, senão figuras cômodas, destinadas a esquematizar cálculos. Mas a filosofia deve perguntar-se por que tais símbolos são mais cômodos que outros e possibilitam ir mais longe. Poderíamos, ao operar com eles, ir ao encontro da experiência, se as noções a que eles correspondem não nos assinalassem pelo menos uma direção em que buscar a representação do real? Ora, a direção que eles indicam não é duvidosa; mostramnos, progredindo por meio da extensão concreta, modificações, perturbações, mudanças de tensão ou de energia, e nada mais. É desse modo, sobretudo, que esses símbolos tendem a juntar-se com a análise puramente psicológica que havíamos inicialmente dado do movimento, e que apresentava para nós, não como uma simples mudança de relação entre objetos aos quais ele se acrescentaria como um acidente, mas como uma realidade verdadeira e de certo modo independente. 
Mas a virtualidade só pôde diferenciar-se a partir dos graus que coexistiam nela. A diferenciação é somente a separação do que coexistia na duração. As diferenciações do impulso vital são mais profundamente os graus da própria diferença. E os produtos da diferenciação são objetos absolutamente conformes ao conceito, pelo menos em sua pureza, porque, na verdade, são tão-somente a posição complementar dos diferentes graus do próprio conceito. É sempre nesse sentido que a teoria da diferenciação é menos profunda que a teoria das nuanças ou dos graus (Deleuze, 2006, p. 62).

O funcionamento dinâmico desse esquematismo pode ser descrito na direção do nível mais profundo até o nível menos profundo, ou seja, de baixo para cima. Assim, quando a virtualidade se realiza, a duração se diferencia pela vida e sob uma forma vital. Por isso, a diferença é vital. Mas essa diferença vital só se realiza a partir da memória ou dos graus que coexistem no virtual. Já diferenciação é o movimento realizado pelo impulso vital de separação desses graus ou nuanças.

Ocorre que essas diferenciações operadas pelo impulso vital também são graus da diferença, contudo são os graus mais profundos. Por fim, existem os produtos oriundos da diferenciação, que são objetos absolutamente iguais ao conceito naquilo que concerne à sua pureza, uma vez que atuam como posição complementar dos diferentes graus do próprio conceito.

Tamanha ação do virtual, a diferenciação, além de ser uma separação dos graus, também é caracterizada por Deleuze como sendo o movimento que deixa de ser em si, mas guarda algo de sua origem. Essa característica, segundo Deleuze, diz respeito à determinada tese de Bergson que "é particularmente célebre: o virtual é a lembrança pura, e a lembrança pura é a diferença". ${ }^{15}$ Essa tese aborda o tema da coexistência do passado com o presente tal qual ele é trabalhado por Bergson em "Matéria e Memória"16 e no "Ensaio sobre os dados imediatos da consciência". ${ }^{17}$

Dessa maneira, Deleuze afirma que a lembrança pura é a diferença em dois sentidos. No primeiro sentido, a diferença é o objeto da lembrança como a semelhança é o objeto da percepção, uma vez que nenhuma lembrança se assemelha à outra e cada lembrança é imediatamente perfeita. No segundo sentido, a lembrança é portadora da diferença, pois à medida que as exigências do presente introduzem alguma semelhança em nossas lembranças, elas também introduzem alguma diferença no presente, permitindo a constituição de cada momento seguinte como algo novo, ou melhor, como uma novidade. 
Para Deleuze, esses dois sentidos, que são pertinentes à relação entre a lembrança pura e a diferença, implicam na elaboração de dois outros sentidos para a própria diferença. Assim, a diferença é, ao mesmo tempo, "o particular que é e o novo que se faz". ${ }^{18}$ Essa fórmula é desdobrada e desenvolvida em "diferença como particularidade" e em "diferença como novidade". A diferença como particularidade é "o particular que é" (primeira parte da fórmula) e a diferença como novidade "é o novo que se faz" (segunda parte da fórmula). A relação entre os dois sentidos ocorre nos graus coexistentes da contração ou na própria memória.

A diferença de particularidade é a maior distensão, um desdobramento, uma expansão da memória. A imagem utilizada por Bergson que Deleuze retoma é a do cone, no qual a base é portadora de lembranças em formas individuais e distintas umas das outras. Por outro lado, consoante com o texto de "Matéria e Memória", quando acontece uma contração, no sentido da base para o topo, todas as lembranças se tornam mais banais e menos individualizadas. Assim, a diferença de particularidade está no limite da distensão ou da expansão e seu processo de individuação será prolongado pela matéria que ela prepara.

Com isso, a matéria e a duração ${ }^{19}$ são apresentadas, respectivamente, como limites extremos da distensão e da contração da memória em meio aos seus infinitos planos virtuais e graus coexistentes. Seguindo essa linha de pensamento, Deleuze expõe, portanto, que o passado puro e o puro presente, ou a lembrança e a percepção, são níveis extremos da própria duração separados por inúmeros graus e nuanças. Não só isso, Deleuze também explica que o puro presente, em oposição ao passado puro como particularidade, decorrente do limite da distensão, será caracterizado como semelhança ou universalidade.

Acerca disso, é prudente lembrar como Deleuze explica que Bergson caracteriza a relação entre a repetição e a diferença. A repetição é uma espécie de diferença sempre exterior de si, que é indiferente a si. A diferença, por sua vez, é uma repetição. A razão disso é que em sua origem a diferença é contração e resultado da contração. Nesse ponto, Deleuze mostra como Bergson está próximo de Hume, ${ }^{20}$ pois ambos usam o exemplo das batidas do relógio para

18 Deleuze (2006, p. 64).

19 Cf: Lapoujade (2013, pp. 23-48).

20 Sobre o tema das relações entre Bergson e Hume no interior do pensamento de Deleuze, é oportuno nos reportarmos à nota de rodapé que está presente na "Apresentação" redigida por David Lapoujade em "A ilha Deserta”. Nessa nota, Lapoujade expõe o projeto inacabado de biografia por parte de Deleuze. Esse projeto divide o conjunto da obra de Deleuze em 11 partes. O detalhe que despertou a nossa atenção é o título da parte I: "De Hume a Bergson". Entendemos que esse título pode significar que os trabalhos de Deleuze sobre Hume e Bergson são colocados em um bloco comum. Nesse sentido, existem dois trabalhos de Deleuze a respeito de David Hume: o livro "Empirismo e Subjetividade", de 1953 e o texto "Hume", de 1972. Assim, o exemplo das batidas do relógio com a finalidade de ilustrar a produção da diferença no espírito é um dos 
mostrar como aquilo que se repete no mundo dos objetos produz a diferença no espírito, mais especificamente as várias batidas sucessivas produzem o espírito enquanto espera pela batida seguinte. Essa espera é o surgimento da diferença.

Nesse caso, os estados que são produzidos pela contração aparecem fundidos entre si e trazendo, ao mesmo tempo, algo da exterioridade da qual eles são oriundos. Se algo da exterioridade faz parte da diferença em função da contração, então a contração permite a coexistência de elementos que se repetiam no aspecto exterior. Portanto, a repetição é distensão e matéria, cujos elementos idênticos são fundidos a cada nova operação da contração.

Essas sucessivas operações da contração terminam por, a princípio, fundir cada elemento da vida material, desfazendo a individualidade de cada um. Esse processo ocorre como se as lembranças fossem repetidas um número indefinido de vezes em cada contração. Contrair significa produzir graus, mas também significa contrair cada um dos graus ou planos já produzidos em cada nova contração, logo cada contração é também a contração de todos os graus, culminando num movimento de repetição, ou seja, a diferença é também uma repetição; e a repetição, como matéria, é o grau mais baixo da duração tomada como diferença.

Posto isso, a oposição entre dois termos na memória, contração/distensão; lembrança/percepção; passado puro/puro presente, é a coexistência virtual entre dois graus extremos. A lembrança coexiste com a percepção correspondente, bem como o puro presente é um grau mais contraído do passado puro. Retomando a dinâmica do esquematismo, é possível entender que dois graus extremos são portadores de uma diferença de natureza ou decorrem de uma diferenciação anterior.

Isso significa que os graus intermediários entre dois extremos estão aptos para restituir esses extremos como produtos do movimento de diferenciação. Esses mesmos graus intermediários formam a ideia geral como todo dinâmico, uma oscilação, que se move entre contração e distensão ou, de modo mais preciso, entre a ação e a memória pura. Os graus intermediários entre os dois extremos são os graus da generalidade que possibilitam a formação da ideia geral, a qual pressupõe uma percepção das semelhanças como movimento de contração.

A ideia geral é um tipo de diferenciação que, na perspectiva dos graus ou planos virtuais, coloca um extremo no outro. Então, a ideia geral é o todo que retomada no início do capítulo 2 de "Diferença e repetição", cujo título é "A repetição para si mesma". 
se diferencia em imagens particulares e atitude corporal, transformando as lembranças em percepções ou atuando na distensão de contrações.

Por consequência, a ideia geral tem duas funções importantes: define a diferença como novidade e efetua a ligação entre a diferença como novidade e a diferença como particularidade. A diferença como novidade decorre da retomada da oposição entre passado, como particularidade, e presente como semelhança ou universal. A ideia geral é esse todo que se movimenta do passado particular para o presente universal, isto é, ela coloca o particular no universal, possibilitando a diferença como novidade ou o particular sendo colocado no universal. De maneira mais precisa, a novidade é o movimento que vai do universal ao particular e do particular ao universal, opondo um ao outro e colocando um no outro.

\section{Considerações finais}

É prudente retomarmos nosso objetivo geral: explicitar o itinerário ou linha argumentativa de Gilles Deleuze no artigo intitulado "A concepção da diferença em Bergson", de 1954. Para atingir semelhante propósito, advogamos que Deleuze expõe a noção de "diferença" presente na obra de Henri Bergson por meio da relação entre três dimensões: metodológica, cosmológica e ontológica.

Para desenvolver essa hipótese, caracterizamos o conjunto do pensamento de Deleuze em relação à História da Filosofia. No passo seguinte, expusemos, grosso modo, o percurso das pesquisas de Deleuze sobre a obra de Bergson. Por fim, explicitamos o itinerário de Deleuze no artigo "A concepção da diferença em Bergson".

Com base nisso, constatamos que o itinerário de Deleuze agrupa a "diferença" em quatro aspectos: diferenças de natureza, diferença interna, diferenciação e, por fim, graus da diferença. Tamanho agrupamento está relacionado com um plano metodológico e com um plano ontológico, que, além de fazerem a constante remissão de um ao outro, também correspondem, respectivamente, ao problema das diferenças de natureza e ao problema da natureza da diferença. Portanto, a diferença na dimensão metodológica equivale ao tema das diferenças de natureza e a diferença na dimensão ontológica está ligada ao problema da natureza da diferença, já o plano cosmológico está ligado às inúmeras tensões e graus dentro dos limites da memória que integra o esquematismo bergsoniano.

\section{Referências}

ALLIEZ, É. "Sobre o bergsonismo de Deleuze". Tradução de Ana Lúcia Oliveira. In: ALLIEZ, É. (Org.). Gilles Deleuze: uma vida filosófica. São Paulo: Ed. 34, 2000. 
BERGSON, H. "A evolução criadora". Tradução de Bento Prado Neto. São Paulo: Martins Fontes, 2005.

. "Ensaio sobre os dados imediatos da consciência". Tradução de João da Silva Gama. Lisboa: Edições 70, [s.d.].

. "Matéria e memória". Tradução de Paulo Neves. São Paulo: Martins Fontes, 1999.

DELEUZE, G. «L'Abecédéraire de Gilles Deleuze - avec Claire Parnet”. Paris: Édtions Montparnasse, 1996 (DVD).

. "Bergsonismo". Tradução de Luiz B. L. Orlandi. São Paulo: Ed. 34, 1999.

. "Conversações". Tradução de Peter Pál Pelbart. São Paulo: Ed. 34, 1992.

. “A concepção da diferença em Bergson”. In: DELEUZE, G. A ilha deserta e outros textos: textos e entrevistas (1953-1974). Tradução de Lia Guarino e Fernando Facundes Ribeiro. Edição preparada por David Lapoujade. São Paulo: Iluminuras, 2006. ."Bergson, 1859-1941". In: DELEUZE, G. A ilha deserta e outros textos: textos e entrevistas (1953-1974). Tradução de Lia Guarino e Fernando Facundes Ribeiro. Edição preparada por David Lapoujade. São Paulo: Iluminuras, 2006.

."Diferença e repetição". Tradução de Roberto Machado e Luiz Orlandi. Rio de Janeiro: Graal, 2006.

DELEUZE, G. ; PARNET, C. « Dialogues ». Paris: Champsessais, 1996.

DOSSE, F. "Gilles Deleuze e Félix Guattari: biografia cruzada". Tradução de Murad. Porto Alegre: Artmed, 2010.

FREITAS, F. “A Diferenciação como interpretação da evolução da vida: breve comentário ao Capítulo 5 do Bergsonismo de Deleuze". Revista Ítaca, Rio de Janeiro, Nr.. 29, pp. 100-117, 2015.

HARDT, M. "Gilles Deleuze: um aprendizado em filosofia". Tradução de Sueli Cavendish. São Paulo: 34, 1996.

LAPOUJADE, D. "Potências do tempo". Tradução de Hortência Santos Lencastre. São Paulo: N 1 edições, 2013.

MORATO PINTO, D. "Crítica do negativo e a virada ontológica em Bergson: a filosofia como pensamento em duração" p. 245- 275. In: MORATO PINTO, D.; MARQUES, S. L. (orgs.). "Henri Bergson - Crítica do negativo e pensamento em duração". São Paulo: Alameda, 2009. 